\title{
Recovery of vision in fulminant idiopathic intracranial hypertension
}

\author{
Andrew Micieli MD, Jonathan A. Micieli MD CM
}

Cite as: CMAJ 2019 June 10;191:E639. doi: 10.1503/cmaj.190024

A previously healthy 20-year-old AfricanCanadian woman presented to the emergency department with blurred vision in her right eye for 3 days and a 6-week history of new-onset headaches, which had worsened substantially over the previous week. The patient also had transient vision "blackouts" that lasted seconds and occurred with changes in position, along with pulsatile tinnitus. She had gained $9 \mathrm{~kg}$ over the past 2 months. She was not taking vitamin A derivatives or tetracyclines.

The patient was admitted to hospital; the magnetic resonance imaging scan of her brain was normal, but magnetic resonance venography of the head showed narrowing of the distal transverse sinuses. Although the patient's visual acuity was normal at presentation, substantial visual field defects and bilateral optic edema were seen on ophthalmologic examination (Figure 1). Lumbar puncture in the left lateral decubitus showed an elevated opening pressure of $>60$ (normal $<25) \mathrm{cm}$ of water with normal cerebrospinal fluid (CSF) contents; her headache improved substantially after the test. We diagnosed idiopathic intracranial hypertension. Given the patient's severe papilledema, visual field defects and headaches that responded to lumbar puncture, she underwent ventriculoperitoneal shunting without complication. Her symptoms and visual function promptly improved and her visual fields returned to normal 1 month later.

Idiopathic intracranial hypertension is a syndrome of raised intracranial pressure with no identifiable cause, such as vitamin $\mathrm{A}$ derivatives or tetracyclines, and is typically seen in young, obese women. ${ }^{1}$ Although patients usually present with chronic symptoms such as headache or incidentally discovered optic disc edema, idiopathic intracranial hypertension may have a fulminant course with rapid onset of symptoms. ${ }^{2}$ These latter patients are at high risk for irreversible vision loss, and surgical intervention such as CSFshunting procedures or optic nerve sheath fenestration is often required. Because prompt recognition is necessary to prevent blindness, fundoscopy is important in patients with new headaches. This can be achieved with an ophthalmology consultation or facilitated with nonmydriatric ocular fundus photography in the emergency department, which has been shown to allow for easy detection of relevant ocular findings. ${ }^{3}$

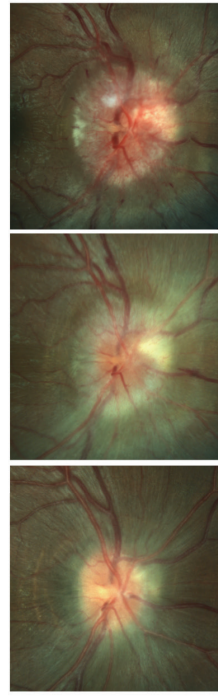

Right eye

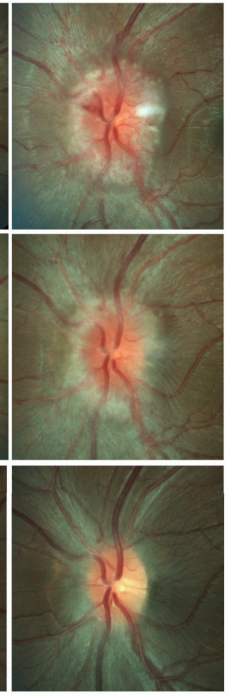

Left eye
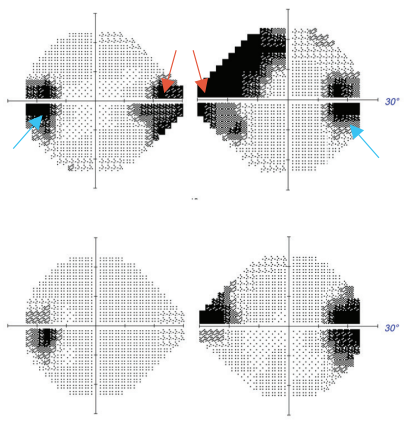

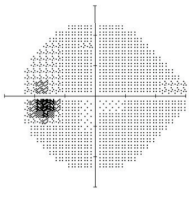

Left eye

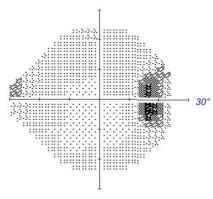

Right eye
Figure 1: Photographs of the optic nerve of a 20-year-old woman, showing severe bilateral optic disc edema at presentation. The edema substantially improved after ventriculoperitoneal (VP) shunt, as seen in the 1-week and 1-month follow-up images. Humphrey 24-2 visual fields at presentation show enlarged blind spots (blue arrows) and nasal steps (red arrows) in both eyes. These visual field defects substantially improved at the follow-up visits.

\section{References}

1. Friedman DI, Liu GT, Digre KB. Revised diagnostic criteria for the pseudotumor cerebri syndrome in adults and children. Neurology 2013;81:1159-65.

2. Thambisetty M, Lavin PJ, Newman NJ, et al. Fulminant idiopathic intracranial hypertension. Neurology 2007;68:229-32.

3. Bruce BB, Lamirel C, Wright DW, et al. Nonmydriatic ocular fundus photography in the emergency department. N Engl J Med 2011;364:387-9.

\section{Competing interests: None declared.}

This article has been peer reviewed.

The authors have obtained patient consent.

Affiliations: Division of Neurology, Department of Medicine (A. Micieli and J.A. Micieli), Department of Ophthalmology and Vision Sciences (J.A. Micieli), University of Toronto, Toronto, Ont.; Kensington Vision and Research Centre (J.A. Micieli), Toronto, Ont.

Correspondence to: Jonathan Micieli, jmicieli@kensingtonhealth.org 